\title{
Selective Monoprotection of Symmetrical Diols in a Flow Reactor
}

\author{
Hisashi Masui, Masaru Takizawa, Yuki Sakai, Yasuhiro Kajiwara, Kiyofumi Wanibuchi, \\ Mitsuru Shoji*, Takashi Takahashi*
}

Department of Pharmaceutical Sciences, Yokohama University of Pharmacy, Yokohama, Japan

Email: *mitsu.shoji@hamayaku.ac.jp, *ttak@hamayaku.ac.jp

How to cite this paper: Masui, H., Takizawa, M., Sakai, Y., Kajiwara, Y., Wanibuchi, K., Shoji, M. and Takahashi, T. (2018) Selective Monoprotection of Symmetrical Diols in a Flow Reactor. International Journal of Organic Chemistry, 8, 264-271. https://doi.org/10.4236/ijoc.2018.82019

Received: May 24, 2018

Accepted: June 19, 2018

Published: June 22, 2018

Copyright $\odot 2018$ by authors and Scientific Research Publishing Inc. This work is licensed under the Creative Commons Attribution International License (CC BY 4.0).

http://creativecommons.org/licenses/by/4.0/

\begin{abstract}
Desymmetrization reactions provide a powerful approach for the construction of complex molecules. Various methods have been developed for the selective monoprotection of symmetrical diols; however, their application to large-scale operations is limited. In this study, the monotetrahydropyranylation of symmetrical diols in a flow reactor has been developed, whereby the length of the flow reactor tube and the amount of acid were optimized. A higher selectivity for the monoprotected derivative was observed when the reaction was performed in a flow reactor compared with that observed in a conventional batch experiment. The efficient flow method developed herein can be applied to large-scale synthesis by numbering up the flow reactor without affecting the selectivity and yield. Since monoprotection can be achieved without using a large excess of diol, our developed flow method is effective when expensive diol must be used.
\end{abstract}

\section{Keywords}

Desymmetrization, Selective Monoprotection, Flow Synthesis, Diols, Tetrahydropyranylation

\section{Introduction}

Desymmetrization reactions have attracted much attention in organic synthesis because they provide a powerful tool to access complex molecules from readily available symmetrical compounds [1] [2]. For instance, the desymmetrization of diols [3] [4] [5] [6] [7], dicarbonyls [8] [9] [10] [11] [12], diamines [13], and alkenes [14] [15] [16] has been successfully applied to the synthesis of natural products such as (-)-spongidepsin [7] and merrilactone A [9] [10]. In particular, the monoprotection of diols with the tetrahydropyranyl (THP) group has been 
widely used in the synthesis of bioactive compounds [17] [18] [19] [20]. However, these transformations usually result in the concomitant generation of unprotected and/or diprotected compounds in a statistical ratio. In order to overcome this limitation, the selective monoprotection of symmetrical diols has been typically performed using an excess of diol. Moreover, catalysts with a relatively small catalytic surface such as ion-exchange resins (namely, Amberlite IR-120 [21], Amberlist H-15 [22], Rellex 425 [23], Dowex 50 [24], and Nafion-H [25]), iodine [26], $\mathrm{ZrO}_{2}$-pillared clay [27], zinc chloride [28], and aqueous acids [29] have been reported to be effective for selective monotetrahydropyranylation. However, the application of these methods to large-scale production for practical use of monoprotected diols is somewhat limited. In particular, it is very wasteful to use a large excess of expensive diol as a substrate.

In recent years, flow chemistry has emerged as an important adjunct to conventional batch chemistry [30] [31]. In a large-scale batch reactor, there is a time lag for the mixed solution to become homogeneous by stirring, which affects both the chemoselectivity and the yield of the reaction. In addition, the reaction parameters must be adapted to each scale-up condition. In contrast, flow chemistry allows for highly chemoselective reactions without side products by precisely controlling the reaction time and temperature. Moreover, flow reactions are scalable under the same conditions by simply numbering up the reactor configuration. On the basis of these advantages, we sought to investigate the selective monoprotection of diols in a flow reactor. The selective mono protection of diols using flow reactor has not been reported yet. We have previously reported the microflow synthesis of peptides using highly activated esters [32], vitamin $\mathrm{D}_{3}$ [33], activated vitamin $\mathrm{D}_{3}$ and its analogs [34], diamine ligands [35], and aliphatic aldehyde [36]. Herein, we report the development of a new method for selective monoprotection of diols in a flow system.

\section{Materials and Methods}

\subsection{General}

NMR spectra were recorded on a JEOL Model ECA-500 instrument, and chemical shifts were reported in parts per million ( $\mathrm{ppm}$ ) relative to internal standard (tetramethylsilane; $0.0 \mathrm{ppm}$ ) or solvent $\left(\mathrm{CDCl}_{3} ; 7.26 \mathrm{ppm}\right.$ for ${ }^{1} \mathrm{H}$ NMR and 77.1 ppm for ${ }^{13} \mathrm{C}$ NMR) peaks. ${ }^{1} \mathrm{H}$ NMR spectral data were reported as chemical shift $(\delta, \mathrm{ppm})$, multiplicity (s, singlet; $\mathrm{d}$, doublet; $\mathrm{t}$, triplet; $\mathrm{q}$, quartet; sp, septet; $\mathrm{m}$, multiplet; br, broad), coupling constant $(J, \mathrm{~Hz})$, and integral value. ${ }^{13} \mathrm{C} \mathrm{NMR}$ data were reported as chemical shift $(\delta, \mathrm{ppm})$ followed by multiplicity and coupling constants where applicable. All reactions were monitored by thin-layer chromatography using $0.25-\mathrm{mm}$ E. Merck silica gel plates (60F-254), with visualization performed by UV light $(254 \mathrm{~nm})$ irradiation or staining with $p$-anisaldehyde, ceric sulfate, or $10 \%$ ethanolic phosphomolybdic acid followed by heating. Column chromatography was performed using silica gel (Chromatorex PSQ 100B, Fuji Silysia Chemical Ltd.). All reagents and chemicals were purchased 
from Tokyo Chemical Industry Co., Ltd., and used as received.

\subsection{General Procedure for the Monotetrahydropyranylation of Diols in a Batch Reactor}

To a solution of 1,4-butanediol (1) (1.00 g, $11.1 \mathrm{mmol}, 1.00$ equiv.) and 3,4dihydro-2 $H$-pyran (1.20 mL, $13.3 \mathrm{mmol}, 1.20$ equiv.) in tetrahydrofuran (11.1 $\mathrm{mL}$ ) was added 10-camphorsulfonic acid (258 $\mathrm{mg}, 1.11 \mathrm{mmol}, 0.100$ equiv.) at room temperature. After being stirred at this temperature, the reaction mixture was quenched with triethylamine and concentrated in vacuo. The residue was diluted with ethyl acetate and saturated aqueous $\mathrm{NaHCO}_{3}$, and the organic layer was washed with brine, dried over $\mathrm{MgSO}_{4}$, filtered, and concentrated in vacuo. The residue was purified by column chromatography on silica gel to give 4-((tetrahydro-2H-pyran-2-yl)oxy)butan-1-ol (2) and

1,4-bis((tetrahydro-2H-pyran-2-yl)oxy)butane (3) [21]. Unreacted 1 was found in the aqueous layer and was quantified $(\mathrm{mmol})$ by the difference between the amount of starting substrate $(11.1 \mathrm{mmol})$ and the amount of product $(\mathrm{mmol})$.

4-((Tetrahydro-2 $H$-pyran-2-yl)oxy)butan-1-ol (2)

${ }^{1} \mathrm{H}$ NMR $\left(500 \mathrm{MHz}, \mathrm{CDCl}_{3}\right): \delta 4.60(\mathrm{dd}, J=2.9,4.0 \mathrm{~Hz}, 1 \mathrm{H}), 3.86(\mathrm{ddd}, J=3.5$, 8.0, $11.4 \mathrm{~Hz}, 1 \mathrm{H}), 3.80(\mathrm{dt}, J=4.9,11.4 \mathrm{~Hz}, 1 \mathrm{H}), 3.67$ (brs, $2 \mathrm{H}), 3.51(\mathrm{dt}, J=5.4$, $10.9 \mathrm{~Hz}, 1 \mathrm{H}), 3.43(\mathrm{dt}, J=5.7,9.8 \mathrm{~Hz}, 1 \mathrm{H}), 2.19$ (brs, $1 \mathrm{H}), 1.81(\mathrm{~m}, 1 \mathrm{H}), 1.75$ $1.66(\mathrm{~m}, 5 \mathrm{H}), 1.61-1.50(\mathrm{~m}, 4 \mathrm{H}) ;{ }^{13} \mathrm{C} \mathrm{NMR}\left(125 \mathrm{MHz}, \mathrm{CDCl}_{3}\right): \delta 99.0,67.6,62.8$, $62.5,30.7,30.2,26.7,25.5,19.6$.

1,4-Bis((tetrahydro-2H-pyran-2-yl)oxy)butane (3)

${ }^{1} \mathrm{H}$ NMR $\left(500 \mathrm{MHz}, \mathrm{CDCl}_{3}\right): \delta 4.58(\mathrm{dd}, J=2.9,4.0 \mathrm{~Hz}, 2 \mathrm{H}), 3.86(\mathrm{ddd}, J=3.1$, 4.0, $11.2 \mathrm{~Hz}, 2 \mathrm{H}), 3.76(\mathrm{~m}, 2 \mathrm{H}), 3.49(\mathrm{~m}, 2 \mathrm{H}), 3.41(\mathrm{~m}, 2 \mathrm{H}), 1.82(\mathrm{~m}, 2 \mathrm{H}), 1.73$ $1.65(\mathrm{~m}, 6 \mathrm{H}), 1.60-1.50(\mathrm{~m}, 8 \mathrm{H}) ;{ }^{13} \mathrm{C} \mathrm{NMR}\left(125 \mathrm{MHz}, \mathrm{CDCl}_{3}\right): \delta 98.9,67.4,62.3$, $30.8,26.7,25.6,19.7$.

\subsection{Flow Reactor Setup}

The flow system used in this work is shown in Figure 1. A stainless steel T-shaped

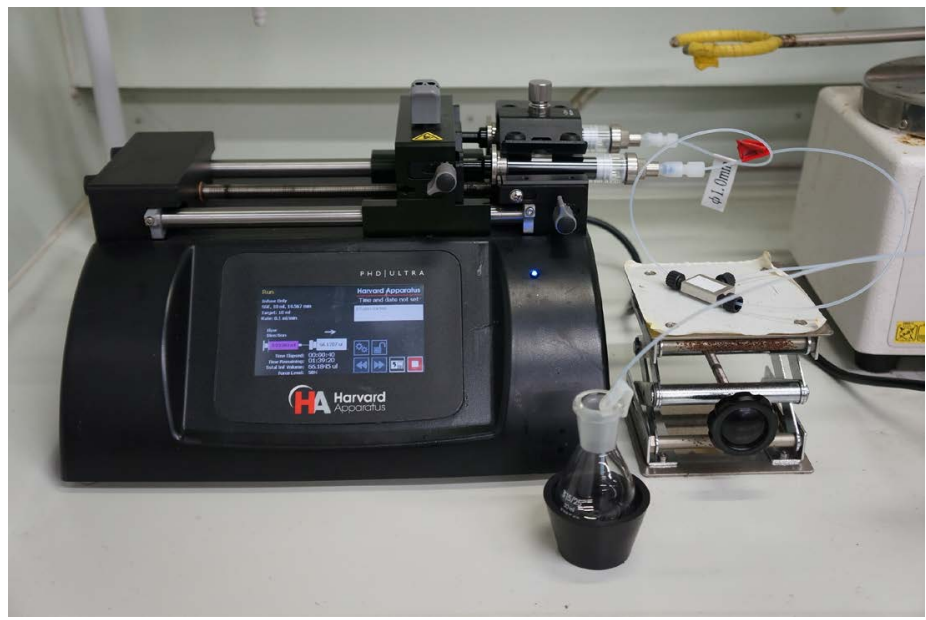

Figure 1. Flow system for tetrahydropyranylation. 
mixer (inner diameter: $1.0 \mathrm{~mm}$ ) and a Teflon ${ }^{\circledR}$ tube (inner diameter: $1.0 \mathrm{~mm}$ ) were purchased from YMC Co. Ltd. The mixer and tube were connected with PEEK fittings, which were also purchased from YMC Co. Ltd. Solutions were introduced into the flow system using a syringe pump (Harvard PHD ULTRA) equipped with gastight syringes (SGE). The gastight syringes and Teflon ${ }^{\circledR}$ tube were connected with joints purchased from YMC Co. Ltd.

\subsection{General Tetrahydropyranylation Procedure}

A solution of 1,4-butanediol (1) (2.0 mM, 1.00 equiv.) and 3,4-dihydro- $2 H$-pyran (2.4 mM, 1.20 equiv.) in tetrahydrofuran (flow rate: 0.1 $\mathrm{mL} / \mathrm{min}$ ) and a solution of 10-camphorsulfonic acid (X equiv.) in tetrahydrofuran (flow rate: $0.1 \mathrm{~mL} / \mathrm{min}$ ) were introduced into the $\mathrm{T}$-shaped mixer at room temperature using the syringe pump. The resulting mixture was passed through the reaction tube (inner diameter: $1.0 \mathrm{~mm}$, length: $\mathrm{Y} \mathrm{cm}$ ) at the same temperature. After elution for $10 \mathrm{~min}$ to reach a steady state, the mixture was poured into triethylamine at room temperature and concentrated in vacuo. The residue was purified by column chromatography on silica gel to give 4-((tetrahydro- $2 \mathrm{H}$ pyran-2-yl)oxy)butan-1-ol (2) and 1,4-bis((tetrahydro-2H-pyran-2-yl)oxy)butane (3).

\section{Results and Discussion}

Prior to the flow experiments, tetrahydropyranylation of symmetrical diols was carried out in a batch reactor. To a solution of 1,4-butanediol (1) and 3,4-dihydro- $2 \mathrm{H}$-pyran (DHP) in tetrahydrofuran (THF) was added

10-camphorsulfonic acid (CSA), a commonly used Brønsted acid, at room temperature (Figure 2). Figure 3 shows the yield of diol 1 and mono- and bis-THP derivatives $\mathbf{2}$ and $\mathbf{3}$ as a function of reaction time; both $\mathbf{2}$ and $\mathbf{3}$ were gradually formed until an equilibrium mixture of 1:2:3 at a ratio of approximately 1:2:1 was reached. Good selectivity for the target product 2 was obtained for a reaction time of 6 - $10 \mathrm{~min}$, although the yield was moderate.

Next, the monoprotection of 1 was performed in a flow reactor. A solution of 1, DHP, and CSA in THF was introduced into a Teflon ${ }^{\circledR}$ tube at room temperature using a syringe pump (Table 1). The flow rate was set at $0.1 \mathrm{~mL} / \mathrm{min}$, and various tube lengths of $50,100,150$, and $250 \mathrm{~cm}$ were examined, which corresponded to reaction times of $2,4,6$, and $10 \mathrm{~min}$, respectively. With a tube length of 50 and $100 \mathrm{~cm}$, the mono-THP product 2 was obtained with high selectivity, although in low yields (entries 1 and 2, respectively). When a 150-cm tube was

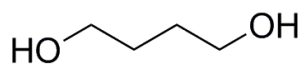

1
3,4-dihydro-2H-pyran CSA, THF

r.t.

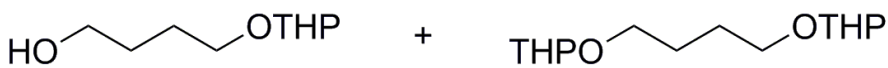

2
3

Figure 2. Tetrahydropyranylation of 1,4-butanediol (1) in a batch reactor. 


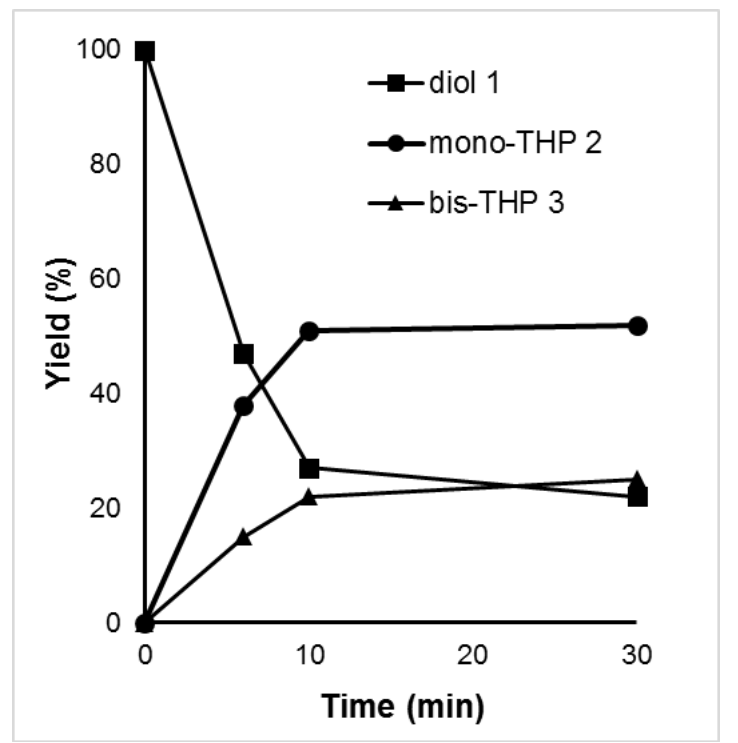

Figure 3. Yield of diol 1 and mono- and bis-THP products 2 and 3 vs reaction time. Mono- and bis-THP product 2 and $\mathbf{3}$ were isolated with column chromatography on silica gel. Unreacted 1 was quantified $(\mathrm{mmol})$ by the difference between the amount of starting substrate $(\mathrm{mmol})$ and the amount of product $(\mathrm{mmol})$.

Table 1. Optimization of selective monotetrahydropyranylation in a flow reactor.

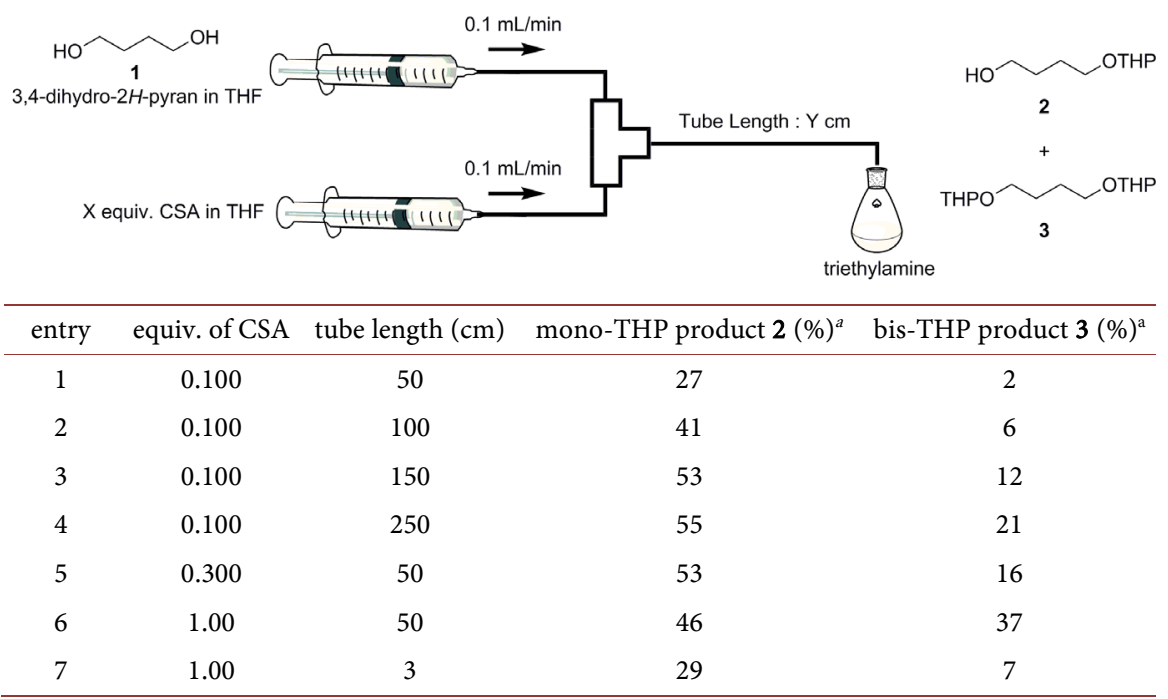

${ }^{\mathrm{a}}$ Isolated yield.

used, the yield of the desired product 2 was improved without an appreciable reduction in selectivity (entry 3 ). A prolonged reaction time resulted in a decrease in selectivity and no improvement in yield (entry 4). The yield was improved when the tube was lengthened, however the byproduct of the bis-protected product also increased. Interestingly, the combination of a $50-\mathrm{cm}$ tube and 0.300 equiv. of CSA (entry 5) gave almost the same result as entry 3 . Moreover, shortening the tube length and increasing the amount of acid was not effective (entries 6 and 7). Hence, the flow synthesis of the mono-tetrahydropyranyl derivative required the use of a $150-\mathrm{cm}$ tube and 0.100 equiv. of CSA to achieve high selectivity and sa- 
tisfactory yield. It should be noted that, under all conditions tested, the starting material was not completely consumed.

\section{Conclusion}

In conclusion, we have developed the monotetrahydropyranylation of symmetrical diols in a flow reactor. Stirring 1,4-butanediol, DHP, and CSA in a batch reactor for $6-10 \mathrm{~min}$ resulted in the selective formation of the monoprotected diol. However, the selectivity for monotetrahydropyranylation improved when the reaction was carried out in a flow reactor. The flow method can be applied directly to large-scale synthesis by simply numbering up the flow reactor without affecting the selectivity and yield. Studies are currently underway to develop a method to remove unreacted starting diol from flow reactors.

\section{Acknowledgements}

This research was partially supported by an ADEKA Award in Synthetic Organic Chemistry, Japan and the Asahi Glass Foundation.

\section{References}

[1] Zeng, X.-P., Cao, Z.-Y., Wang, Y.-H., Zhou, F. and Zhou, J. (2016) Catalytic Enantioselective Desymmetrization Reactions to All-Carbon Quaternary Stereocenters. Chemical Reviews, 116, 7330-7396. https://doi.org/10.1021/acs.chemrev.6b00094

[2] Wang, M., Feng, M., Tang, B. and Jiang, X. (2014) Recent Advances of Desymmetrization Protocol Applied in Natural Product Total Synthesis. Tetrahedron Letters, 55, 7147-7155. https://doi.org/10.1016/j.tetlet.2014.10.152

[3] Maezaki, N., Kojima, N., Sakamoto, A., Iwata, C. and Tanaka, T. (2001) First Total Synthesis of Mosin B. Organic Letters, 3, 429-432.

https://doi.org/10.1021/ol006938e

[4] Werness, J.B. and Tang, W. (2011) Stereoselective Total Synthesis of (-)-Kumausallene. Organic Letters, 13, 3664-3666. https://doi.org/10.1021/ol201477u

[5] Trost, B.M. and Mino, T. (2003) Desymmetrization of Meso 1,3- and 1,4-Diols with a Dinuclear Zinc Asymmetric Catalyst. Journal of the American Chemical Society, 125, 2410-2411. https://doi.org/10.1021/ja029708z

[6] Lee, W., Youn, J.H. and Kang, S.H. (2013) Total Synthesis of (-)-Kaitocephalin. Chemical Communications, 5231-5233. https://doi.org/10.1039/c3cc42365d

[7] Ghosh, A.K. and Xu, X. (2004) Assignment of Absolute Stereochemistry and Total Synthesis of (-)-Spongidepsin. Organic Letters, 6, 2055-2058. https://doi.org/10.1021/ol049292p

[8] Simpkins, N.S. and Gill, C.D. (2013) Asymmetric Total Synthesis of the Proposed Structure of the Medicinal Alkaloid Jamtine Using the Chiral Base Approach. Or ganic Letters, 5, 535-537. https://doi.org/10.1021/ol027447s

[9] Inoue, M., Sato, T. and Hirama, M. (2003) Total Synthesis of Merrilactone A. Journal of the American Chemical Society, 125, 10772-10773. https://doi.org/10.1021/ja036587+

[10] Inoue, M., Lee, N., Kasuya, S., Sato, T., Hirama, M., Moriyama, M. and Fukuyama Y. (2007) Total Synthesis and Bioactivity of an Unnatural Enantiomer of Merrilactone A: Development of an Enantioselective Desymmetrization Strategy. Journal of 
Organic Chemistry, 72, 3065-3075. https://doi.org/10.1021/jo0700474

[11] Chen, Z.H., Chen, Z.M., Zhang, Y.Q., Tu, Y.Q. and Zhang, F.M. (2011) Total Synthesis of $( \pm)$-Maistemonine, $( \pm)$-Stemonamide, and $( \pm)$-Isomaistemonine. Journal of Organic Chemistry, 76, 10173-10186. https://doi.org/10.1021/jo202042x

[12] Elamparuthi, E., Fellay, C., Neuburger, M. and Gademann, K. (2012) Total Synthesis of Cyrneine A. Angewandte Chemie International Edition, 51, 4071-4073. https://doi.org/10.1002/anie.201200515

[13] Snell, R.H., Woodward, R.L. and Willis, M.C. (2011) Catalytic Enantioselective Total Synthesis of Hodgkinsine B. Angewandte Chemie International Edition, 50, 9116-9119. https://doi.org/10.1002/anie.201103864

[14] Yadav, J.S., Rajender, V. and Rao, Y.G. (2010) Total Synthesis of Pteridic Acid A. Organic Letters, 12, 348-350. https://doi.org/10.1021/ol9026842

[15] Nagatomo, M., Koshimizu, M., Masuda, K., Tabuchi, T., Urabe, D. and Inoue, M. (2014) Total Synthesis of Ryanodol. Journal of the American Chemical Society, 136, 5916-5919. https://doi.org/10.1021/ja502770n

[16] Ghosh, A.K. and Anderson, D.D. (2012) Enantioselective Total Synthesis of Pladienolide B: A Potent Spliceosome Inhibitor. Organic Letters, 14, 4730-4733. https://doi.org/10.1021/ol301886g

[17] Qiu, Y. and Li, D. (2006) Bifunctional Inhibitors of Mevalonate Kinase and Mevalonate 5-Diphosphate Decarboxylase. Organic Letters, 8, 1013-1016. https://doi.org/10.1021/ol052573s

[18] Makabe, H., Kimura, Y., Higuchi, M., Konno, H., Murai, M. and Miyoshi, H. (2006) Synthesis of $(4 R, 15 R, 16 R, 21 S)$ - and $(4 R, 15 S, 16 S, 21 S)$-Rollicosin, Squamostolide, and Their Inhibitory Action with Bovine Heart Mitochondrial Complex I. Bioorganic \& Medicinal Chemistry, 14, 3119-3130. https://doi.org/10.1016/j.bmc.2005.12.015

[19] Gogoi, S. and Argade, N.P. (2008) Synthesis of Norpandamarilactonines, Pandamarilactonines, and -Pandanamine. Synthesis, No. 9, 1455-1459.

[20] Sabitha, G., Padmaja, P., Sudhakar, K. and Yadav, J.S. (2009) Total Synthesis of the $Z$-Isomers of Nonenolide and Desmethyl Nonenolide. Tetrahedron: Asymmetry, 20, 1330-1336. https://doi.org/10.1016/j.tetasy.2009.05.002

[21] Nishiguchi, T., Kawamine, K. and Ohstuka, T. (1992) Highly Selective Monoetherification of Symmetrical Diols Catalysed by Metallic Sulfate Supported on Silica Gel. Journal of the Chemical Society, Perkin Transactions, 1, 153-156. https://doi.org/10.1039/p19920000153

[22] Bongini, A., Cardillo, G., Orena, M. and Sandri, S. (1979) A Simple and Practical Method for Tetrahydropyranylation of Alcohols and Phenols. Synthesis, No. 8, 618-620. https://doi.org/10.1055/s-1979-28784

[23] Johnston, R.D., Marston, C.R., Krieger, P.E. and Goe, G.L. (1988) A New, Mild Heterogeneous Catalyst for the Tetrahydropyranylation of Alcohols and Phenols. Synthesis, 393-394. https://doi.org/10.1055/s-1988-27587

[24] Nishiguchi, T., Fujisaki, S., Kuroda, M., Kajisaki, K. and Saitoh, M. (1998) Selective Monotetrahydropyranylation of Symmetrical Diols Catalyzed by Ion-Exchange Resins. Journal of Organic Chemistry, 63, 8183-8187. https://doi.org/10.1021/jo980659b

[25] Olah, G.A., Husain, A. and Singh, B.P. (1983) Catalysis by Solid Superacids; $19^{1}$. Simplified and Improved Polymeric Perfluorinated Resin Sulfonic Acid (Nafion-H) Catalyzed Protection-Deprotection Reactions. Synthesis, 892-895.

https://doi.org/10.1055/s-1983-30553 
[26] Deka, N. and Sarma, J.C. (2001) Microwave-Mediated Selective Monotetrahydropyranylation of Symmetrical Diols Catalyzed by Iodine. Journal of Organic Chemistry, 66, 1947-1948. https://doi.org/10.1021/jo000863a

[27] Singh, V., Sapehiyia, V. and Kad, G.L. (2004) Novel Heterogeneously Catalysed Selective, Solventless Monotetrahydropyranylation of Different Symmetrical 1,n-diols and Various Alcohols Using $\mathrm{ZrO}_{2}$-Pillared Clay. Catalysis Communications, 5, 463-468. https://doi.org/10.1016/j.catcom.2004.05.013

[28] Ranu, B.C. and Saha, M. (1994) A Simple, Efficient, and Selective Method for Tetrahydropyranylation of Alcohols on a Solid Phase of Alumina Impregnated with Zinc Chloride. Journal of Organic Chemistry, 59, 8269-8270. https://doi.org/10.1021/jo00105a054

[29] Nishiguchi, T., Hayakawa, S., Hirasaka, Y. and Saitoh, M. (2000) Selective Monotetrahydropyranylation of $1, n$-diols Catalyzed by Aqueous Acids. Tetrahedron Letters, 41, 9843-9846. https://doi.org/10.1016/S0040-4039(00)01742-1

[30] Yoshida, J., Takahashi, Y. and Nagaki, A. (2013) Flash Chemistry: Flow Chemistry That Cannot Be Done in Batch. Chemical Communications, 49, 9896-9904. https://doi.org/10.1039/C3CC44709J

[31] Movsisyan, M., Delbeke, E.I.P., Berton, J.K.E.T., Battilocchio, C., Ley, S.V. and Stevens, C.V. (2016) Taming Hazardous Chemistry by Continuous Flow Technology. Chemical Society Reviews, 45, 4892-4928. https://doi.org/10.1039/C5CS00902B

[32] Fuse, S., Mifune, Y. and Takahashi, T. (2014) Efficient Amide Bond Formation through a Rapid and Strong Activation of Carboxylic Acids in a Microflow Reactor. Angewandte Chemie International Edition, 53, 851-855. https://doi.org/10.1002/anie.201307987

[33] Fuse, S., Tanabe, N., Yoshida, M., Yoshida, H., Doi, T. and Takahashi, T. (2010) Continuous-Flow Synthesis of Vitamin $\mathrm{D}_{3}$. Chemical Communications, 46, 8722 8724. https://doi.org/10.1039/c0cc02239j

[34] Fuse, S., Mifune, Y., Tanabe, N. and Takahashi, T. (2012) Continuous-Flow Synthesis of Activated Vitamin $\mathrm{D}_{3}$ and Its Analogues. Organic \& Biomolecular Chemistry, 10, 5205-5211. https://doi.org/10.1039/c2ob25511a

[35] Fuse, S., Tanabe, N., Tannna, A., Konishi, Y. and Takahashi, T. (2013) Micro-Flow Synthesis and Structural Analysis of Sterically Crowded Diimine Ligands with Five Aryl Rings. Beilstein Journal of Organic Chemistry, 9, 2336-2343. https://doi.org/10.3762/bjoc.9.268

[36] Masui, H., Honda, E., Niitsu, S., Shoji, M. and Takahashi, T. (2018) Safe Hydroformylation of Aliphatic Alkene in a Flow Reactor. International Journal of Organic Chemistry, 8, 135-141. https://doi.org/10.4236/ijoc.2018.81009 